\title{
Parallel distribution compensation PID based on Takagi-Sugeno fuzzy model applied on Egyptian load frequency control
}

\author{
M. A. Abdel Ghany ${ }^{1}$, Mohamed A. Shamseldin² \\ ${ }^{1}$ Department of Electrical Engineering, Faculty of Engineering, October 6 University, Egypt \\ ${ }^{2}$ Faculty of Engineering and Technology, Future University in Egypt, Egypt
}

\begin{tabular}{l} 
Article Info \\
\hline Article history: \\
Received Oct 26, 2019 \\
Revised Feb 23, 2020 \\
Accepted Apr 25, 2020 \\
\hline Keywords: \\
Fuzzy \\
Parallel distribution \\
PID \\
Power system control \\
Takagi-Sugeno
\end{tabular}

\section{Corresponding Author:}

Mohamed A. Shamseldin,

Faculty of Engineering and Technology,

Future University in Egypt,

90th St, First New Cairo, Cairo Governorate 11835, Egypt

Email: Mohamed.abelbbar@fue.edu.eg

\begin{abstract}
This paper presents a new technique for a Takagi-Sugeno (TS) fuzzy parallels distribution compensation-PID'S (TSF-PDC-PID'S) to improve the performance of egyptian load frequency control (ELFC). In this technique, the inputs to a TS fuzzy model are the parameters of the change of operating points. The TS fuzzy model can definite the suitable PID control for a certain operating point. The parameters of PID'S controllers are obtained by ant colony optimization (ACO) technique in each operating point based on an effective cost function. The system controlled by the proposed TSF-PDCPID'S is investigated under different types of disturbances, uncertainty and parameters variations. The simulation results ensure that the TSF-PDC-PID'S can update the suitable PID controller at several operating points so, it has a good dynamic response under many types of disturbances compared to fixed optimal PID controller.
\end{abstract}

Copyright $@ 2020$ Institute of Advanced Engineering and Science. All rights reserved.

\section{INTRODUCTION}

The Egyptian power system consists of different types of generating stations, which can be classified into the three types [1]. The first type stations having non-reheat generating units such as gas turbine power stations and few steam power stations [2]. The second type, stations having reheat generating units such as the majority of thermal stations and combined cycle power stations [3]. The third type, the hydro-electric power stations $[4,5]$. The Egyptian power system contains seven zones: Cairo, Middle Egypt, Upper Egypt, East El-Delta, El-Canal, West El-Delta and Alexandria, as shown in Figure 1. The seven zones are strongly tied together forming one area power system [6-10].

Each of the first five zones contains both reheat and non-reheat power stations, while the north upper Egypt zone contains only reheat power stations and the last zone-south upper Egypt zone-contains only hydro power stations. Each zone comprises several power plants (non-reheat, reheat, and hydro power plants or a combination of them) $[9,10]$.The Egyptian power system data including the type and number of generating units in each station, the rating and inertia constant of different units, and the inherent reserve in each unit are given in [7-9]. The incompatibility between electric power generation and load demand causes a frequency deviation in addition to tie-line power deviation in the interconnected power system. Also, the large value of frequency deviation reasons several disturbances such as destroying the equipment, transmission line overloading and interference with system protection [6].

To avoid such problem, several load frequency control (LFC) techniques are presented to keep the system frequency at nominal value [1]. The objectives of LFC are to minimize the transient deviations in area frequency and tie-line power interchange and to ensure their steady state errors to be zeros [2]. Although 
the active power and reactive power have combined effects on the frequency and voltage, the control problem of the frequency and voltage can be decoupled [3]. The frequency is highly dependent on the active power while the voltage is highly dependent on the reactive power [4]. According to the most recent research, several control strategies were implemented in the LFC loops of different power systems [5].

The main disadvantage of integral LFC was the poor dynamic response of the system while high gain may cause instability for the system [8]. The conventional PID controllers for LFC were applied on several engineering applications due to their structure simplicity and easy to implementation [9]. Moreover, the PID controllers are suitable for on-line applications due to its simple calculations and its fast response [10]. The PID controllers have a good performance for a certain operating point while it may give a poor response at change the operating point for the system. In addition, it cannot deal with the system nonlinearity and uncertainty [11].

To develop the performance of the PID controllers, several approaches based on tuning algorithms have been proposed. The tuning algorithms of PID gains include the traditional and intelligent adjustments. The famous traditional method is the Ziegler-Nichols that suggested rules for obtaining the proper PID controller parameters [12]. Recently, several optimization techniques (such as genetic algorithm, particle swarm optimization, simulating annealing, evolutionary programming, bacterial foraging, ant colony and agent reinforcement learning) have been applied to power system to tune the PID controllers for LFC system as promising new tools to improve the performance of the controller for certain operating condition [13].

The previous studies use the fuzzy logic control for nonlinear systems [14]. Especially, the TS fuzzy model has been usually subjected to the control design of nonlinear systems [15], since it can merge the advantages of both fuzzy logic theory and linear system theory [16]. The Fuzzy logic theory aids us to use qualitative [17], linguistic information about a complex nonlinear system to execute the task of the modeling and control design into a group of linear systems [18].

Different fuzzy techniques such as fuzzy PID, fractional-order fuzzy PID, fuzzy factional-order PID tuned via relative rate observer for the ELFC were proposed in [19]. Using these techniques, different changes in the system operating points and parameter variations under drives disturbances were implemented to test the validities of the controller [20]. The operation of the fuzzy techniques based on self-tuning to update scaling factor of the fuzzy normalizing gains during system operating points [21].

In this paper, it is assumed that the ELFC controlled system has different optimal PID controllers corresponding to their operating points [22]. The parameters of PID controllers have been obtained using the ACO technique according to an effective cost function [23]. For each operating point the system is controlled by optimal PID and denotes by a linear subsystem [24]. A new technique of parallel distribution compensation PID controllers based on TS fuzzy mechanism are combined of these linear systems together to obtain the overall complex model and control design [25]. Although the fuzzy controller is constructed using a certain operating point while the feedback gains should be estimated at all operating conditions to guarantee the global stability and control performance [26, 27]. The TSF-PDC-PID is designed to select the suitable OPID controller according to operating point condition for Egyptian load frequency control (ELFC) [28-30].

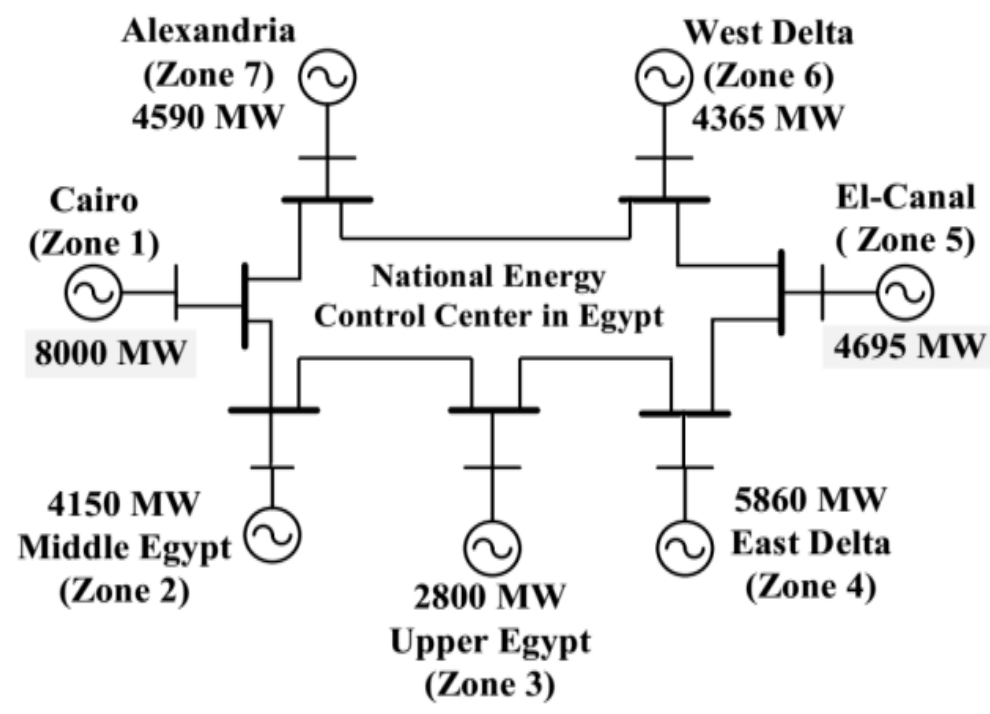

Figure 1. Typical single-line diagram of Egyptian power system [10] 


\section{THE EGYPTIAN LFC SYSTEM}

The EPS's total installed generation capacity and peak load were, respectively, about $22500 \mathrm{MW}$ and $19740 \mathrm{MW}$ in 2008 [7]. The EPS was incorporating about 180 generating units belonging to the following categories [8]:

- None reheat generating units represented by gas turbine power stations and few steam power stations which is about $24 \%$ of the installed capacity [9].

- Reheat generating units represented by the majority of thermal stations and combined cycle power station which is about $62 \%$ of the installed capacity [10].

- Hydroelectric power stations which is about $14 \%$ of the installed capacity [11].

The national energy control center NECC of the Egyptian Electricity Authority has developed a dynamic power frequency model for the EPS [12]. The NECC model is originally built for solving load shedding problems and considers only the effect of primary reserve. The EPS consists of seven strongly tied zones. These zones have not considered any interconnection details and the study is carried out based on single area power system model [12]. The validity of the model has been tested through two different generator outage contingencies in two different loading conditions [28].

Figure 2 shows the block diagram of the Egyptian Power System LFC model as represented by Simulink $[10,12]$. The parameters of this model are divided into two sets. The first set of parameters does not depend on system operating conditions. Table 1 lists the values of those parameters as estimated by NECC [7-12]. The other set of parameters changes with time according to the operating condition. The data required to calculate the changing parameters are concerned with the data of each generator including: status (ON or OFF), type of unit (non reheat, reheat, or hydro), unit rating (MW), unit output (MW) for the operating condition under study, inertia of the unit, and the spinning reserve of the unit in percentage of the unit rating.

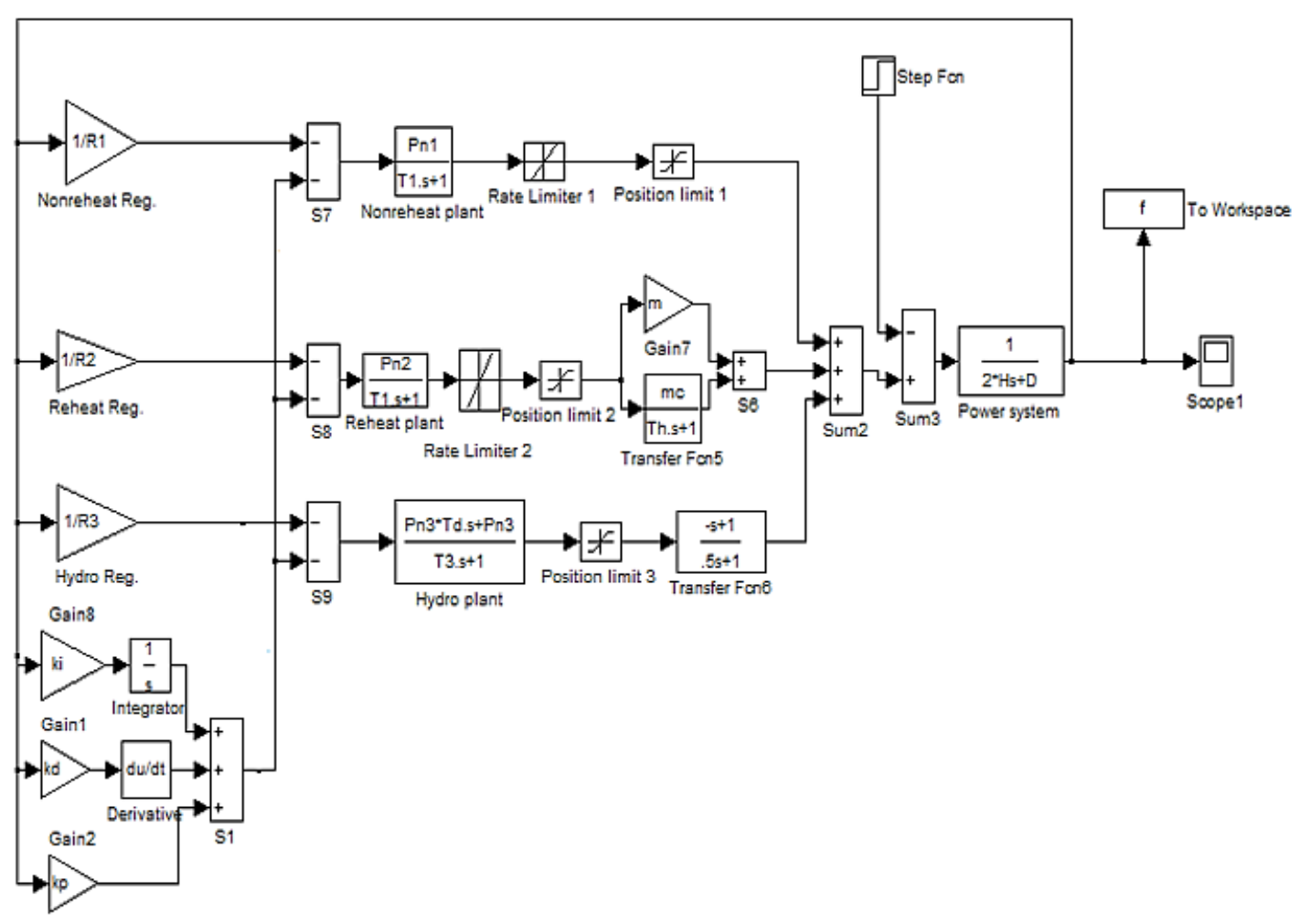

Figure 2. The block diagram of the Egyptian power system LFC model in Simulink representation

The Simulink model considers the generating rate constraints GRC for different generating units. The applied values for GRC are $0.1 \mathrm{p} . \mathrm{u} \mathrm{MW} / \mathrm{min}$ and $0.2 \mathrm{p} . \mathrm{u} \mathrm{MW} / \mathrm{min}$. for reheat turbines and non reheat turbines, respectively. The GRC of hydro plants is neglected since its actual value is much greater corresponding to the time durations of practical disturbances. Where the NECC in Egypt estimates the system parameters values, which are used in the nonlinear model of the EPS are given with per unit in Table 1 [9]. 
Table 1. Egyptian LFC parameters

\begin{tabular}{cccccc}
\hline Parameter & Value & Parameter & Value & Parameter & value \\
\hline $\mathrm{D}$ & 0.028 & $\mathrm{R} 1$ & 2.5 & $\mathrm{Tw}$ & 1.0 \\
$\mathrm{~T} 1$ & 0.4 & $\mathrm{R} 2$ & 2.5 & $\mathrm{RL}$ & 0.8 \\
$\mathrm{~T} 2$ & 0.4 & $\mathrm{R} 3$ & 1.0 & $\mathrm{TL}$ & 2.5 \\
$\mathrm{~Tb}$ & 6 & $\mathrm{Td}$ & 5 & & \\
$\mathrm{M}$ & 0.5 & $\mathrm{~T} 3$ & 90 & & \\
\hline
\end{tabular}

Four loading conditions of the EPS are considered to design the ACO-based PID gains. These four loading conditions represent the max and min loads in two daily load curves of the EPS in 2008 [7], which are the two days of the max water discharge Monday 30/6/2008 and the min water discharge Tuesday 8/1/2008 from hydro power plants [8]. Four MATLAB $\mathrm{m}$-files are used to calculate the changing parameters of the Simulink model [9]. Each m-file contains 6 data sets for each of the 180 generating units installed at 2008 [10]. The first one indicates whether the unit is ON or OFF, while the second one is for the generating unit type [11]. The third and the fourth are for the rating and operating MW of the unit. The fifth and the sixth are for the unit inertia and the unit reserve in percent of its rating. Table 2 shows the calculated parameters out of the four $\mathrm{m}$-files for the four considered operating conditions [12].

Table 2. Operating conditions of EPS at 2008

\begin{tabular}{cccccccc}
\hline Operating point & $\mathrm{H}$ & Pn1 & Pn2 & Pn3 & Pc1 & Pc2 & Pc3 \\
\hline 1 & 5.7096 & 0.2529 & 0.6107 & 0.1364 & 2.87 & 6.51 & 1.25 \\
2 & 6.0168 & 0.3002 & 0.5200 & 0.1798 & 2.95 & 6.73 & 2.18 \\
3 & 5.8552 & 0.2433 & 0.6179 & 0.1389 & 3.24 & 7.12 & 2.38 \\
4 & 6.1452 & 0.3335 & 0.5455 & 0.1210 & 3.36 & 8.07 & 6.05 \\
\hline
\end{tabular}

\section{THE PROPOSED CONTROLLER}

This section illustrates the design steps of proposed the parallel distributed compensation-PID'S to improve the performance the frequency $(\Delta \mathrm{f})$ and the controllers outputs of Egyptian load frequency control system.

\subsection{The parallel distributed compensation-PID 'S}

The parallel distributed compensation (PDC) offers a procedure to design a fuzzy controller from a given T-S fuzzy model [25]. To realize the PDC, a controlled object (nonlinear system) is first represented by a T-S fuzzy model [26]. In the PDC design, each control rule is designed from the corresponding rule of a T-S fuzzy model [27]. The constructing following fuzzy controller via the PDC is given by [28]: Control Rule $i$ :

if

$$
Z_{I}(t) \text { is } M_{i I} \ldots \text {. and } Z_{P}(t) \text { is } M_{i P} \text { then } u(t)=u^{(i)}=k_{p}{ }^{(i)} \cdot e+k_{i}^{(i)} \cdot \int e d t+k_{d}{ }^{(i)} . \Delta e
$$

where $\quad i=1,2, \ldots r$

For building the model using a TS fuzzy model, the ranges of each parameter (pn1, pn2, pn3) according to the Table 2 divides to named membership functions, as shown in Figures 3-5. The membership functions are assumed to be overlapped triangular shapes that have their middle vertexes positioned at the given crisp values and in a manner that assures that at any other crisp value is covered by exactly 2 membership functions.

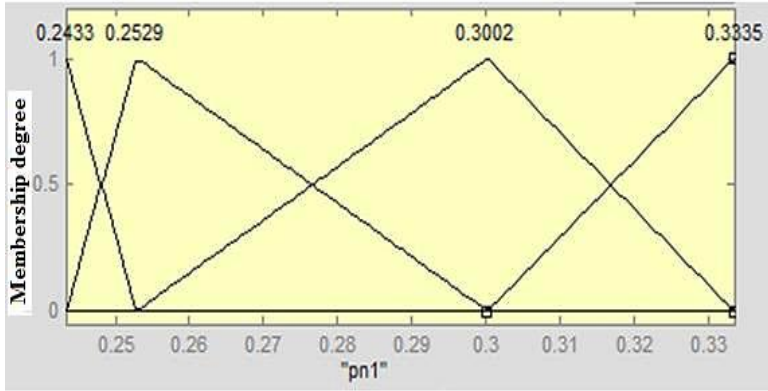

Figure 3. Membership functions for pn1

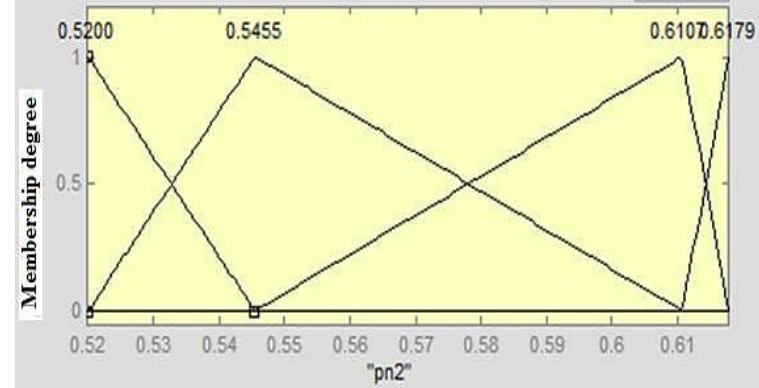

Figure 4. Membership functions for pn2 


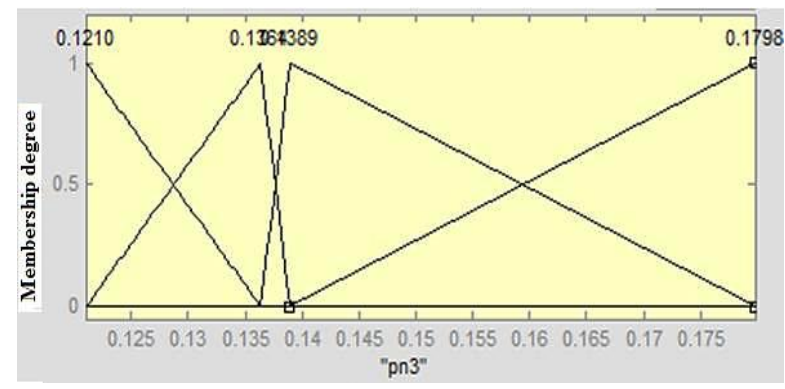

Figure 5. Membership functions for pn3

The Steps of controller design:

- Calculate the weight for each rule as follows:

$$
\text { The weight of } i_{\text {th }} \text { rule is } w_{i}=\min \left(m f_{1}\left(p_{n 1}\right), m f_{2}\left(p_{n 2}\right), m f_{3}\left(p_{n 3}\right)\right)
$$

The ith weight is achieved by using triangle functions and a min block as seen in Figure 6 product block can also used instead of min):

- Calculate the output of the controller as demonstrated in Figure 7 by implementing the following:

$$
u=\frac{\sum_{i=1}^{r}\left(u^{(i)} \cdot W_{i}\right)}{\sum_{i=1}^{r} W_{i}}
$$

Let's take for example, Rule 1:

IF pn1 is about 0.2529 (the value of pn1 that corresponds to rule 1) AND pn2 is about 0.6107 (the value of pn2 that corresponds to rule 1) AND pn3 is about 0.1364 (the value of pn3 that corresponds to rule 1) then,

$$
u=u^{(1)}=1.8912 e+0.088697 \int e d t+0.9733 . \Delta e
$$

Figure 8 shows the operation of the TS Fuzzy model for obtaining a best choice of variations of operating point operation. The operation is verifying (3).

\subsection{The ant colony optimization algorithm (ACO)}

The ant colony optimization algorithm (ACO) is a probabilistic technique to be subjected to solve engineering problems to can find out suitable paths through graphs by decreasing the computational effort [31]. The first application, such algorithm was directed to search for an optimal path in a graph, based on the behavior of ants looking for a path between their colony and a source of food. In the environmental, ants initially search randomly and upon finding food return to their colony while laying down pheromone trails [32]. If other ants find such a path, they do not travel at random, but they follow the trail instead, returning and reinforcing such path if they eventually find food [33]. Over time, the pheromone trail begins to evaporate yielding to reducing its attractive strength [34]. The ant spends more time to travel down the path and back again, the pheromones should evaporate with time [35]. Accordingly, a short path gets marched over more frequently and thus the pheromone density becomes higher on shorter paths than longer ones [36]. Figure 9 demonstrates the behavior of real ants in finding the source of food.

In this method, the actual closed-loop specification of the system combined with the controller, $\operatorname{tr}, M p, t s$, and ess are used to evaluate the fitness function. This is done by summing the squares of the errors between actual and specified specifications as given below [37].

$$
\mathrm{J}=\frac{1}{\left[C_{1}\left(t_{r}-t_{r d}\right)+C_{2}\left(M_{p}-M_{p d}\right)+C_{3}\left(t_{s}-t_{s d}\right)+C_{4}\left(e_{s s}-e_{s s d}\right)\right.}
$$

Where, $c_{1}: c_{4}$ are positive constants (weighting factor), their values are chosen according to prioritizing their importance, $\left(t_{r d}\right)$ is the desired rise time, $\left(\mathrm{M}_{\mathrm{pd}}\right)$ is the desired maximum overshoot, $(\mathrm{tsd})$ is the desired settling time, and (essd) is the desired steady state error [38-42]. Table 3 illustrates the calculated optimal values of the tuned ACS-PID's using cost function given by (5). 


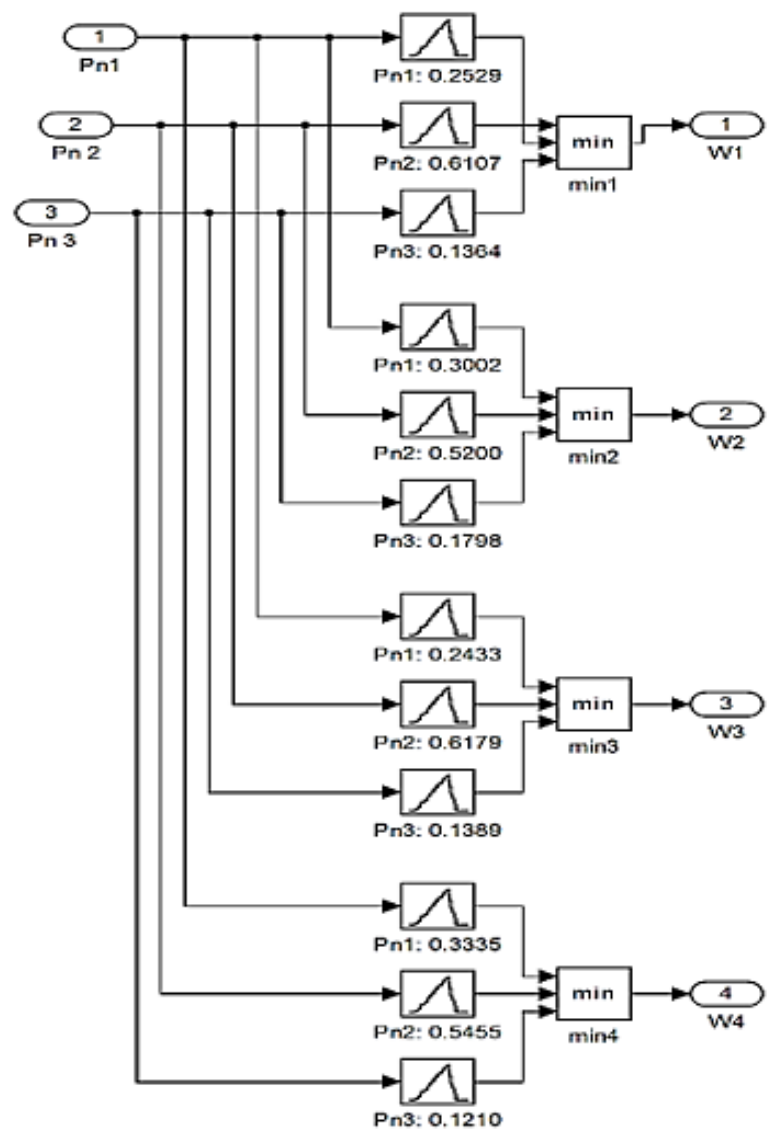

Figure 6. Calculating the weight of one fuzzy rule

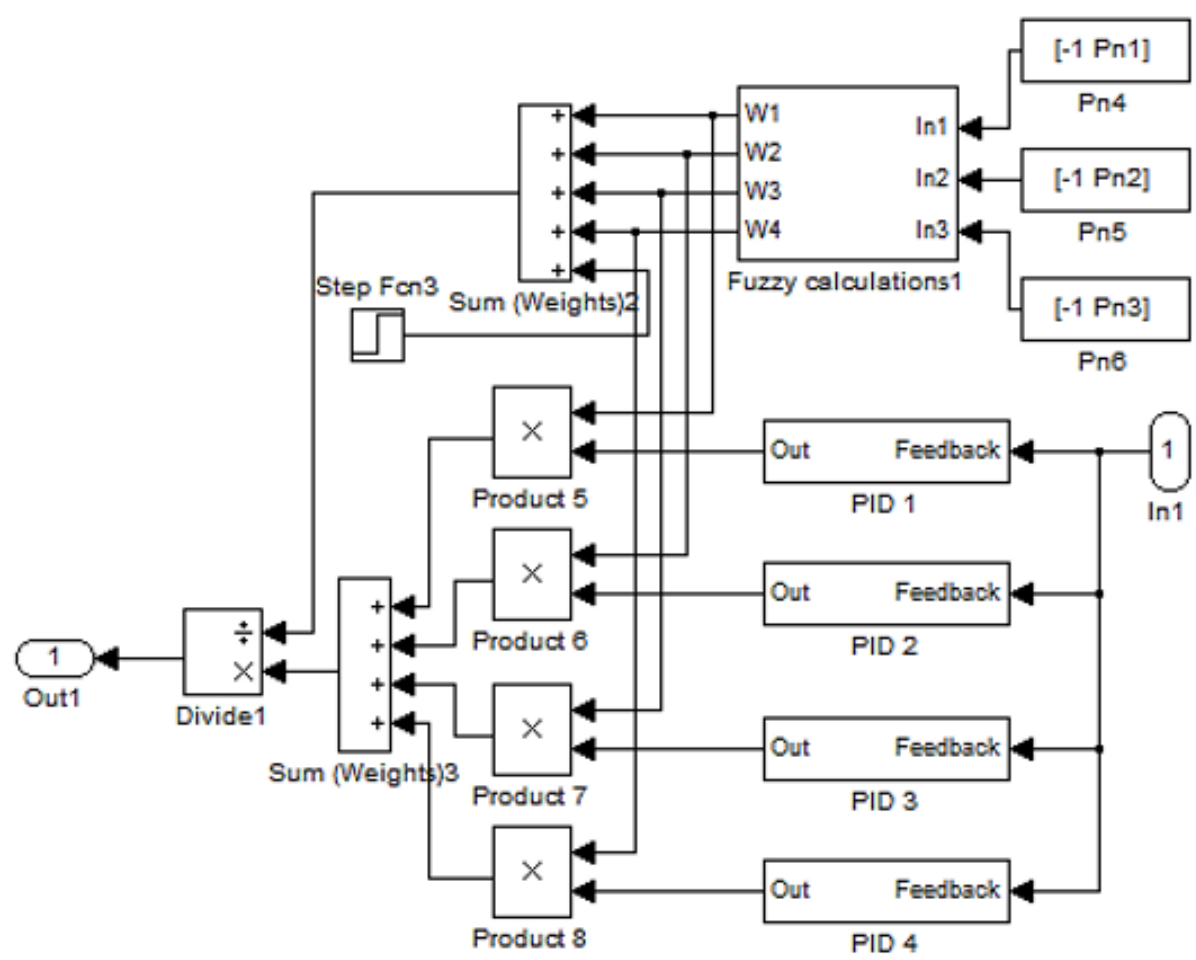

Figure 7. The block diagram of the PDC PID controller 


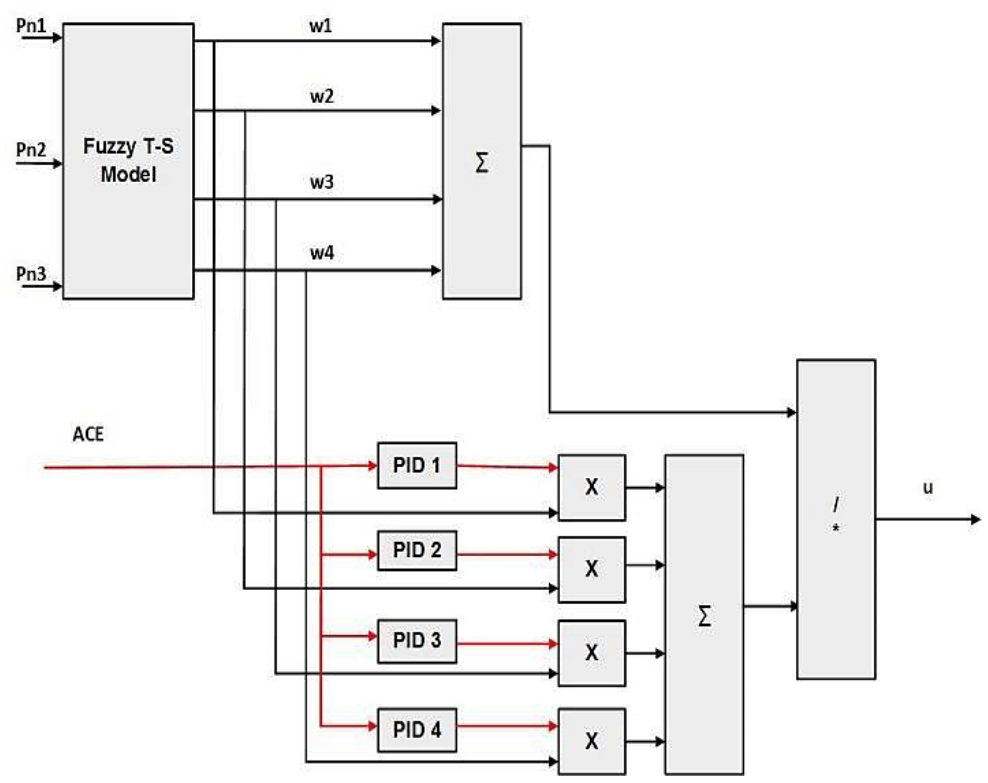

Figure 8. Best choice of operating points using TS fuzzy model

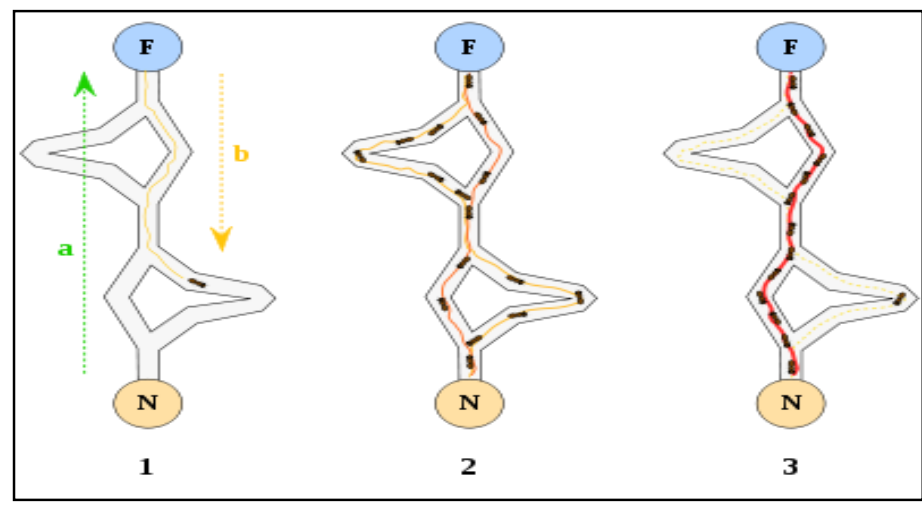

Figure 9. Ants from nest to the source of food

Table 3. The obtained PID'S controller parameters optimized by Ant colony

\begin{tabular}{ccccc}
\hline Operating point & Controller & $\mathrm{kp}$ & $\mathrm{ki}$ & $\mathrm{kd}$ \\
\hline 1 & PID1 & 1.8912 & 0.088697 & 0.97333 \\
2 & PID2 & 1.8271 & 0.089623 & 0.96467 \\
3 & PID3 & 1.5074 & 0.059246 & 0.958 \\
4 & PID4 & 1.2144 & 0.093972 & 0.97133 \\
\hline
\end{tabular}

\section{THE SIMULATION RESULTS}

The simulation results are obtained using MATLAB Toolbox. Different types of disturbances are implemented to ELFC to show the effectiveness of the TSF-PDC-PID'S. Many cases under drives disturbances with different operating points, parameter variation and parameter uncertainty are performed.

\subsection{Case 1: Step disturbance $\Delta P d=5 \%$}

In this test, the controlled of ELFC operates at operating point No. 1 with a $5 \%$ step disturbance is applied to investigate the proposed controllers (the ACS-PID 1 and the TSPDC-PID 1). ACS-PID 1 means that OPID obtained from ELFC offline using ACS optimization at operating point No. 1. The dynamic response of the frequency deviation $\Delta \mathrm{F}$ and the control input are displayed in Figure 10. It is noted that the ACS-PID -1 results are identical with TSPDC-PID 1 at the same operating point. Moreover, the outputs of the controllers (the ACS-PID 1 and the TSPDC-PID 1) have the same response significantly. This verify that TSF-PDC-PID'S operates with high quality as compared with ACS-PID 1. 


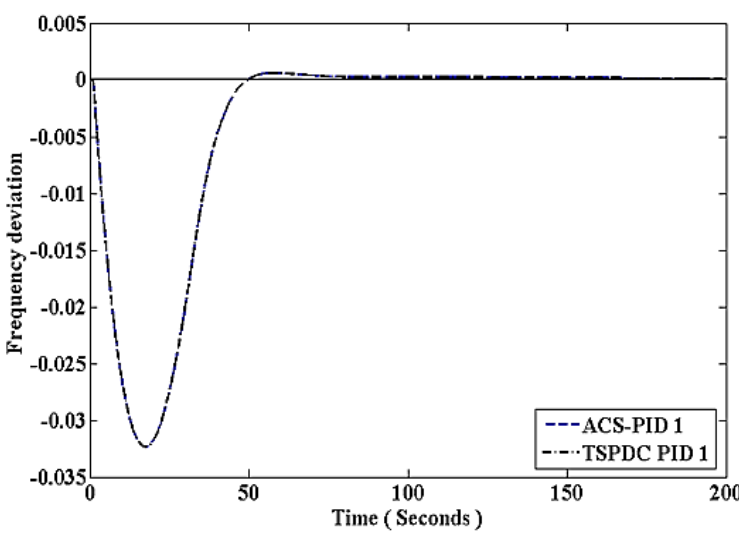

(a)

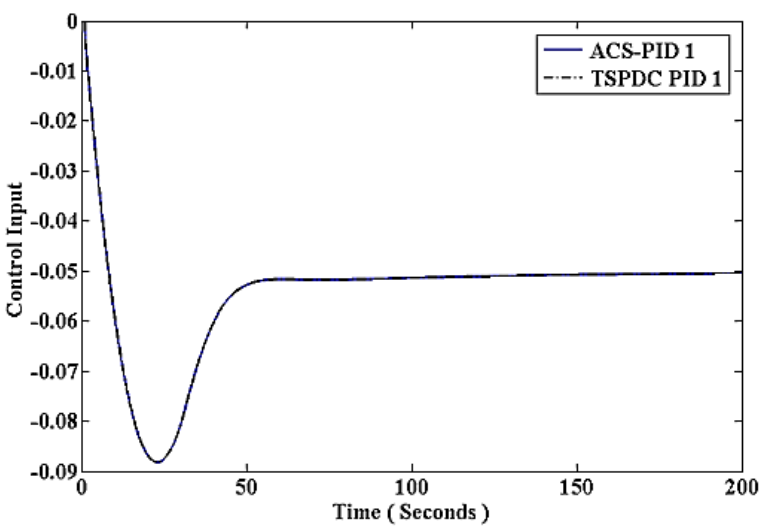

(b)

Figure 10. System dynamic responses case 1, (a) frequency deviation response and (b) control output response

\subsection{Case 2: Trapezoidal change in the disturbance $\Delta \mathbf{P d}$}

This case investigates the proposed controllers (the ACS-PID 1 and the TSPDC-PID 2) when the operating point changes from 1 to 2. ACS-PID 1 means that ELFC operates with operating point no. 2 while the ACS-PID 1 is still unchanged. During the simulation the $\Delta \mathrm{Pd}$ increases gradually to $2 \%$ within $15 \mathrm{~s}$ and then, its value is still fixed from range $15 \mathrm{~s}$ to $37 \mathrm{~s}$ and finally, it decreases regularly to zero as shown in Figure 11(a). The frequency $\Delta \mathrm{f}$ responses and controller outputs are shown in Figures 11(b) and (c), respectively. Clearly, the system response using TSPDC-PID 2 has a small settling and rise time with low overshoot compared to the ACS-PID 1.

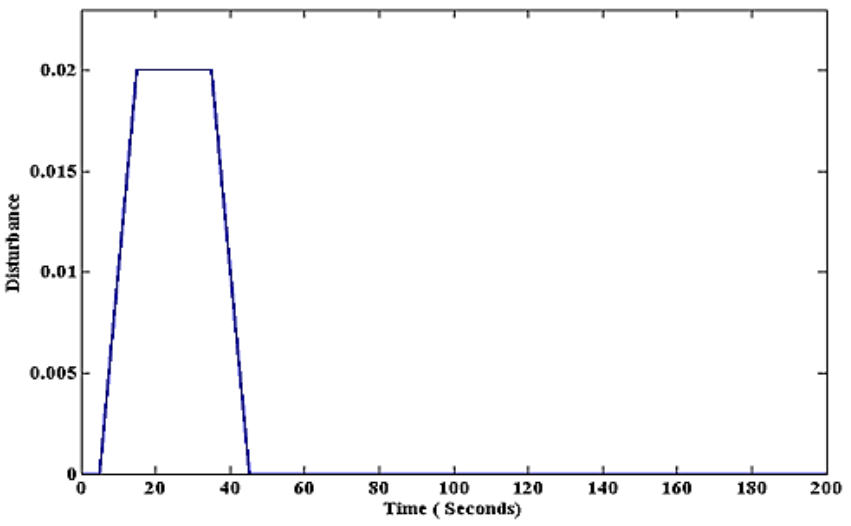

(a)

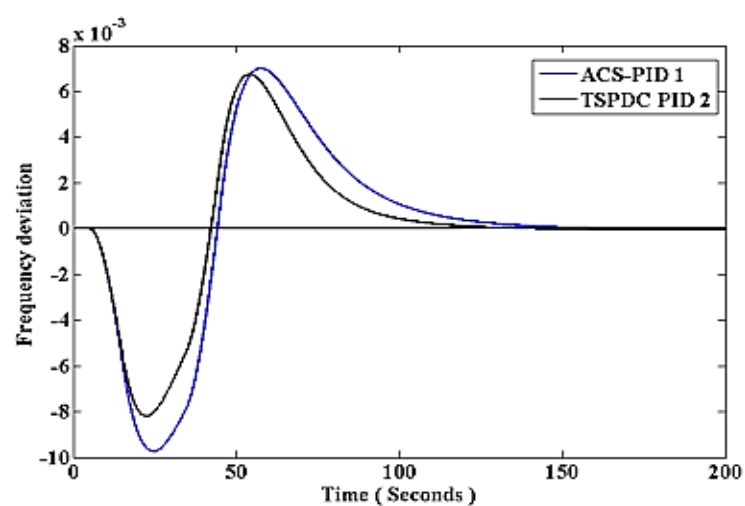

(b)

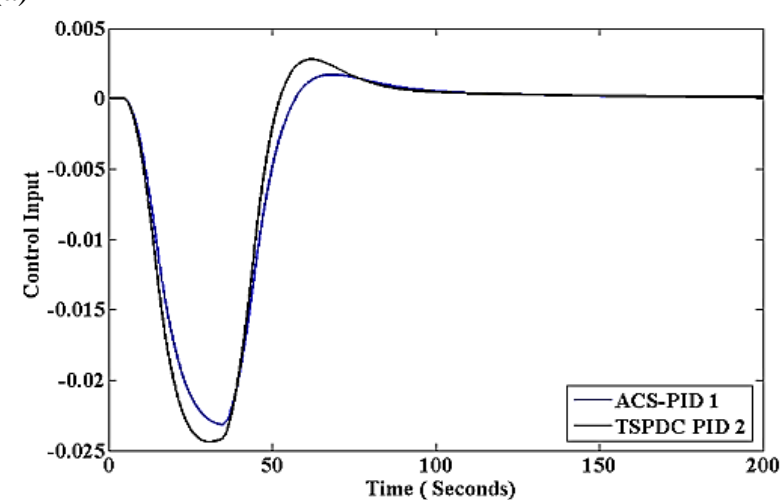

(c)

Figure 11. System dynamic responses case 2, (a) load disturbance,

(b) frequency deviation response and (c) control input response 


\subsection{Case 3: Step decrease (step-down) in $\Delta \mathbf{P d}$}

In this test, the ELFC operates at operating condition No. 3 with a constant disturbance of $3 \%$ is applied for $37 \mathrm{~s}$ then a variation in $\Delta \mathrm{Pd}$ (step decrease to $1 \%$ ) as shown in Figure 12 (a) is subjected to drive the system with each of the controllers; ACS-PID 1 and TSPDC-PID 3. The performance of frequency $\Delta \mathrm{f}$ and the controller outputs are shown in Figures 12 (b) and 12 (c), respectively. As noticed, the system response with TSPDC-PID 3 gives the fastest response (small settling and rise time with low overshoot as compared to the others).

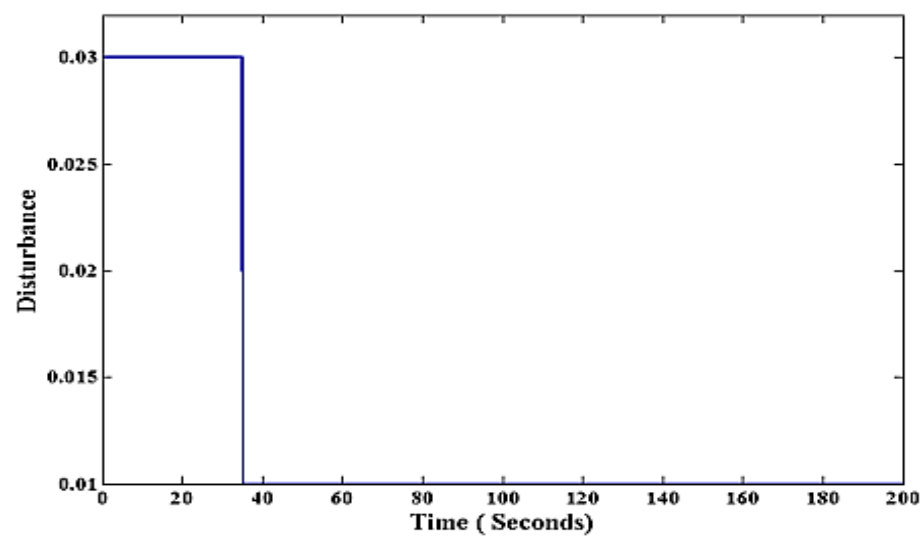

(a)

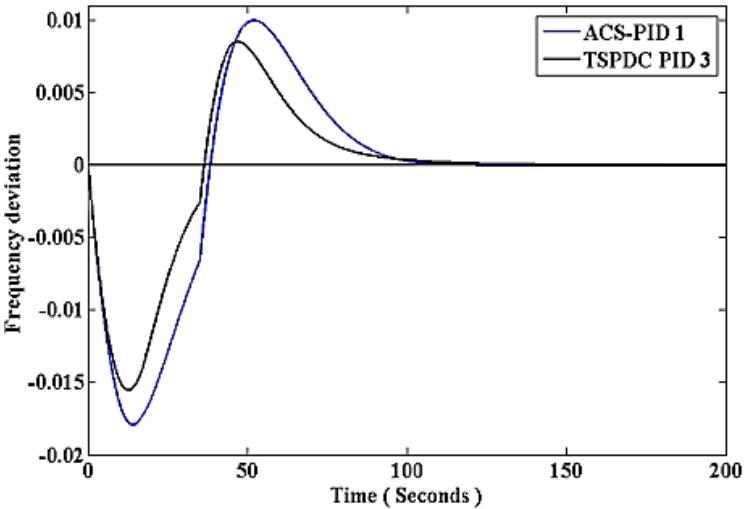

(b)

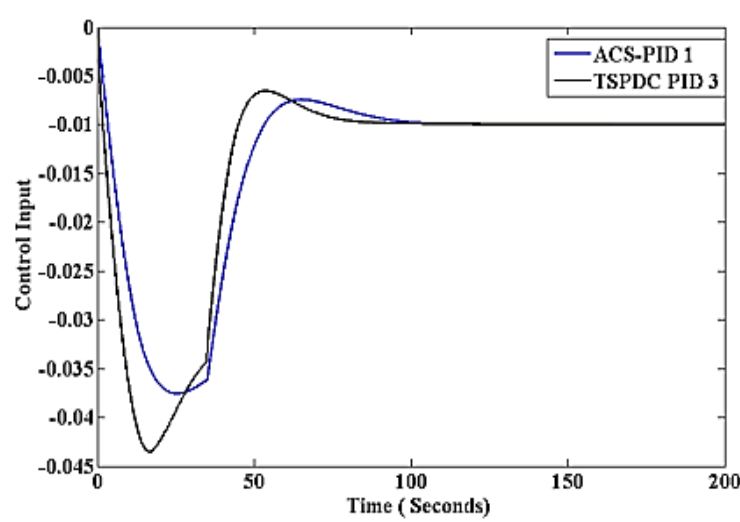

(c)

Figure 12. System dynamic responses case 3, (a) load disturbance, (b) frequency deviation response and (c) control output response

\subsection{Case 4: Comparison between ACS-PID 1 and PDC-PID 3 through tracking-response}

The disturbances of $\Delta \mathrm{Tm}$ and $\Delta$ Vref represented by a 0.05 step change from zero to 60 seconds, then, they decreased to 0.03 from 60 seconds to 110 seconds and finally, they reduced to 0.01 as shown in Figure 13(a). Also, Figures 13(b) and (c) show the system responses driven by TSPDC-PID 3 and ACS-PID 1 controller. It is seen that the TSPDC-PID 3 overcomes these variations and gives a good response where a small settling time is achieved. The control output $(\Delta \mathrm{u})$ of the TSPDC-PID 3 has a good performance that is characterized by similar responses of tracking references with faster responses.

\subsection{Case 5: Parameters variation}

To test the robustness of the proposed controller associated with system parameters change, the values of R1, R2, R3, T1, T2, Tw, Th and Td will increase by 40\% from their nominal values as shown in Table 4. The simulation results are implemented at operating point No. 4. From Figure 14, it is clear that the system responds smoothly with some oscillations during the disturbances is applied. However, the TSPDC-PID 4 has a small effect for parameter changes where the system accommodates with low overshoot and faster response than the ACS-PID1. 


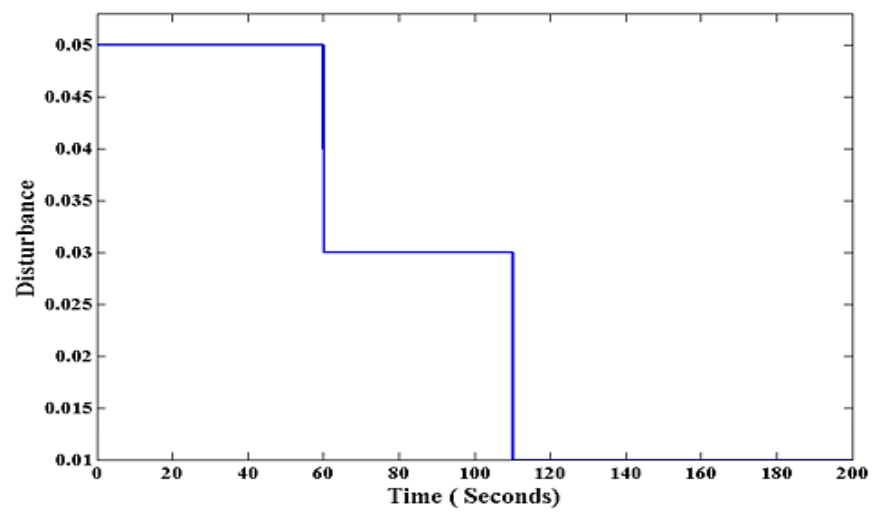

(a)

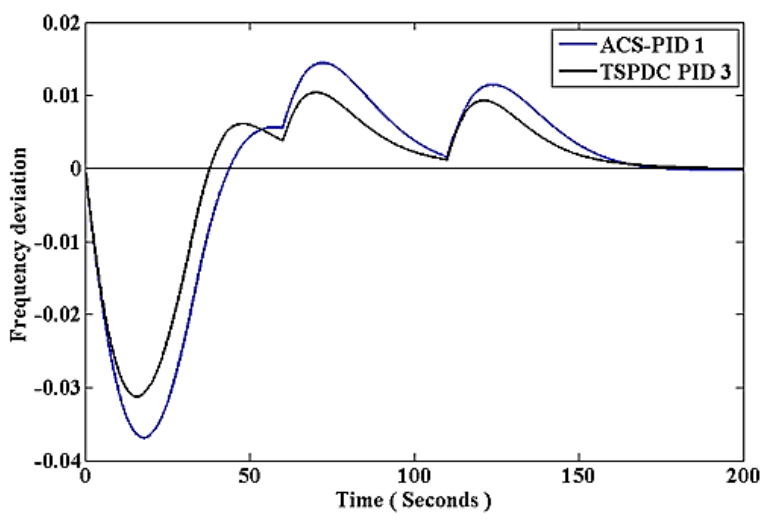

(b)

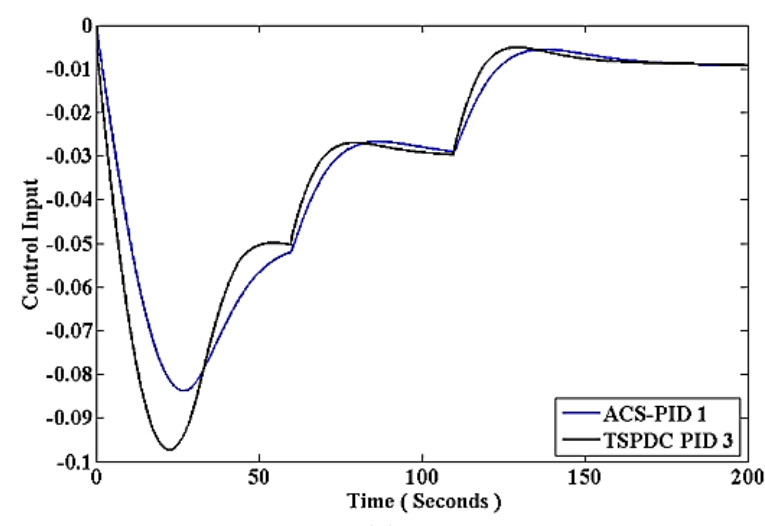

(c)

Figure 13. System dynamic responses case 4, (a) load disturbance, (b) frequency deviation response and (c) control output response

Table 4. Egyptian LFC parameters (Normal) and (+40\%)

\begin{tabular}{ccc}
\hline Parameters & Normal Value & Parameters variation \\
\hline R1 & 2.5 & $\mathbf{3 . 5}$ \\
R2 & 2.5 & $\mathbf{3 . 5}$ \\
R3 & 1.0 & $\mathbf{1 . 4}$ \\
T1 & 0.4 & $\mathbf{0 . 5 6}$ \\
T2 & 0.4 & $\mathbf{0 . 5 6}$ \\
Th & 6 & $\mathbf{8 . 4}$ \\
Td & 5 & $\mathbf{7}$ \\
\hline
\end{tabular}

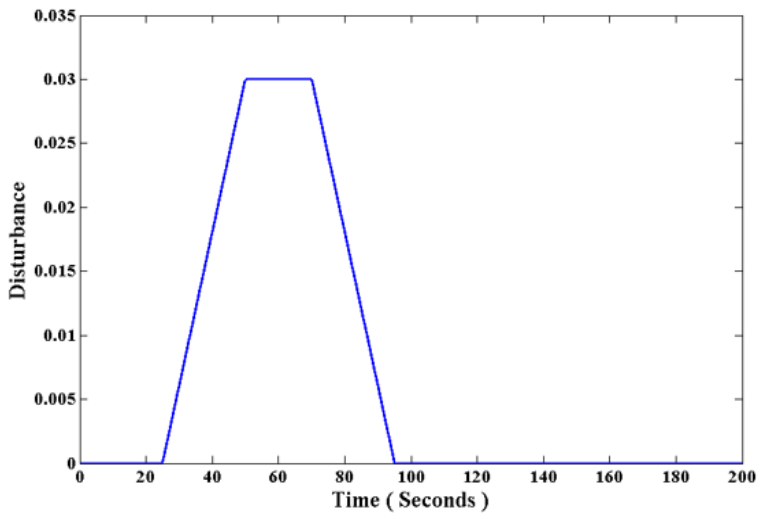

(a)

Figure 14. System dynamic responses case 5, (a) load disturbance 


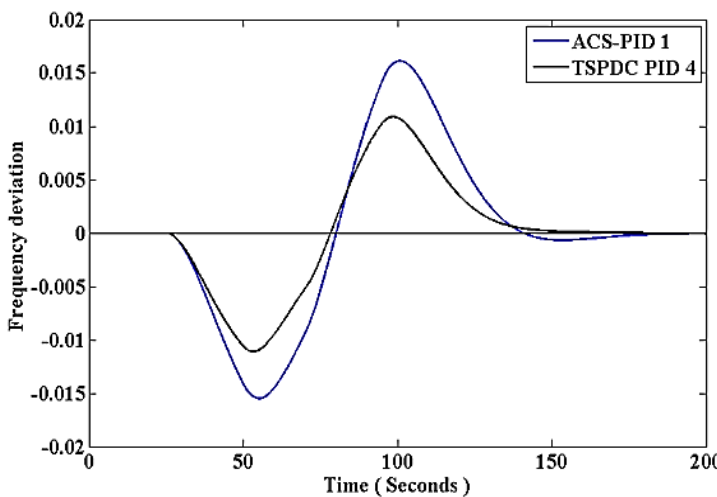

(b)

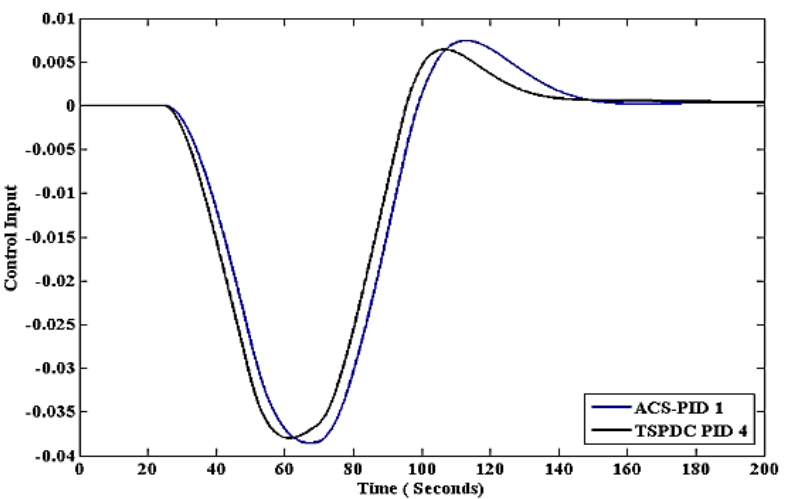

(c)

Figure 14. System dynamic responses case 5, (b) frequency deviation response and (c) control output response (continue)

\subsection{Case 6: Uncertainty in parameters}

In this test, a comparison between the system driven by ACS-PID 1 and TSPDC-PID 2 under a relative disturbance $\Delta \mathrm{Pd}=2 \%$ is applied during $5 \leq \mathrm{t} \leq 30$ seconds and $\Delta \mathrm{Pd}=0 \%$ during $0 \leq \mathrm{t} \leq 5$ seconds. With different system parameter values, is carried out. The system is operated by the EPS-LFC with operating point No. 2. The parameters are changed as follows: from 0-60 (40\% Value), 60-120 (-40\% Value), $120-180$ (40\% Value), 180-200 (+40\% Value), as shown in Tables 5-7 and Figure 15. The time response of the frequency deviation $\Delta \mathrm{F}$ and the control input deviation $\Delta \mathrm{U}$ are shown in Figure 16. Again, the proposed controller TSPDC-PID 2 shows a great improvement in the system frequency than the other two with fewer overshoots and shorter settling time. The control input $\Delta \mathrm{U}$ shows less effort made as compared to the other two.

Table 5. Egyptian LFC parameters (Normal)

\begin{tabular}{cccccc}
\hline Parameter & value & Parameter & value & Parameter & Value \\
\hline D & 0.028 & R1 & 2.5 & Tw & 1 \\
T1 & 0.4 & R2 & 2.5 & RL & 0.8 \\
T2 & 0.4 & R3 & 1.0 & TL & 2.5 \\
Th & 6 & Td & 5 & & \\
M & 0.5 & T3 & 90 & & \\
\hline
\end{tabular}

Table 6. Egyptian LFC parameters $(+40 \%)$

\begin{tabular}{cccccc}
\hline Parameter & value & Parameter & value & Parameter & Value \\
\hline D & 0.028 & R1 & 3.5 & Tw & 1 \\
T1 & 0.56 & R2 & 3.5 & RL & 0.8 \\
T2 & 0.56 & R3 & 1.4 & TL & 2.5 \\
Th & 8.4 & Td & 7 & & \\
M & 0.5 & T3 & 90 & & \\
\hline
\end{tabular}

Table 7. Egyptian LFC parameters (-40\%)

\begin{tabular}{cccccc}
\hline Parameter & value & Parameter & value & Parameter & Value \\
\hline D & 0.028 & R1 & 1.5 & Tw & 1 \\
T1 & 0.24 & R2 & 1.5 & RL & 0.8 \\
T2 & 0.24 & R3 & 0.6 & TL & 2.5 \\
Th & 3.6 & Td & 3 & & \\
m & 0.5 & T3 & 90 & & \\
\hline
\end{tabular}

\begin{tabular}{|l|l|l} 
From 0 to 60 & \multicolumn{2}{c}{ From 120 to 180} \\
\cline { 2 - 3 } Increase $40 \%$ & From 60 to 120 & From 180 to 200 \\
Decrease $40 \%$ & & Decrease $40 \%$
\end{tabular}

Figure 15. Parameters variation 


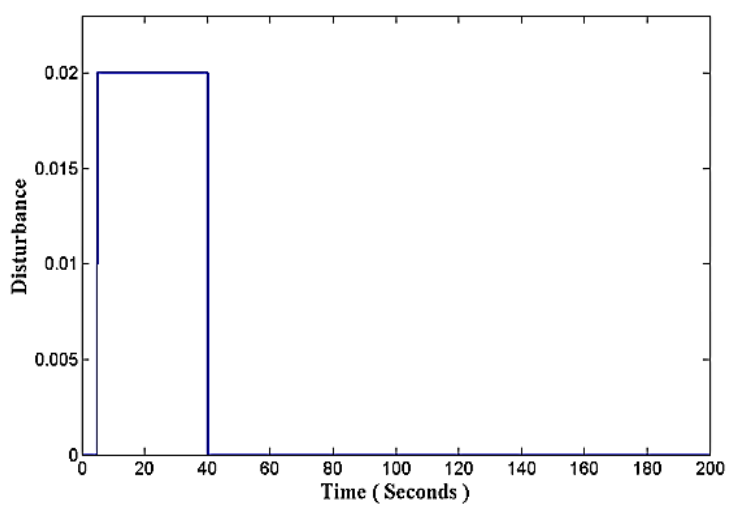

(a)

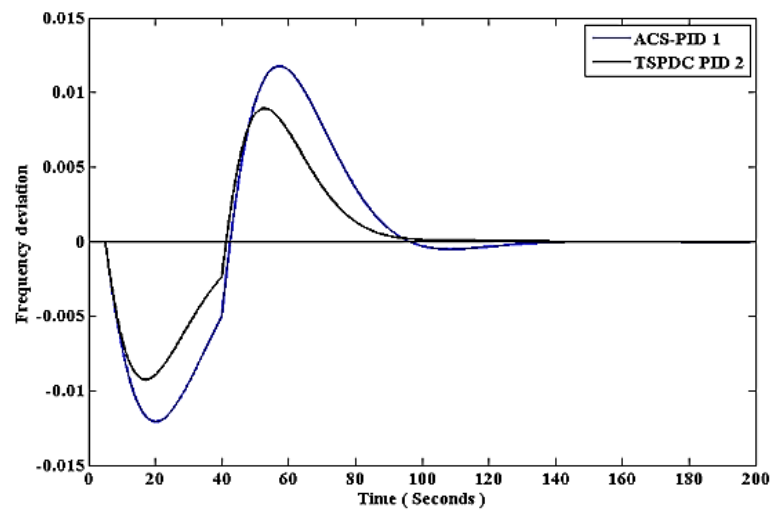

(b)

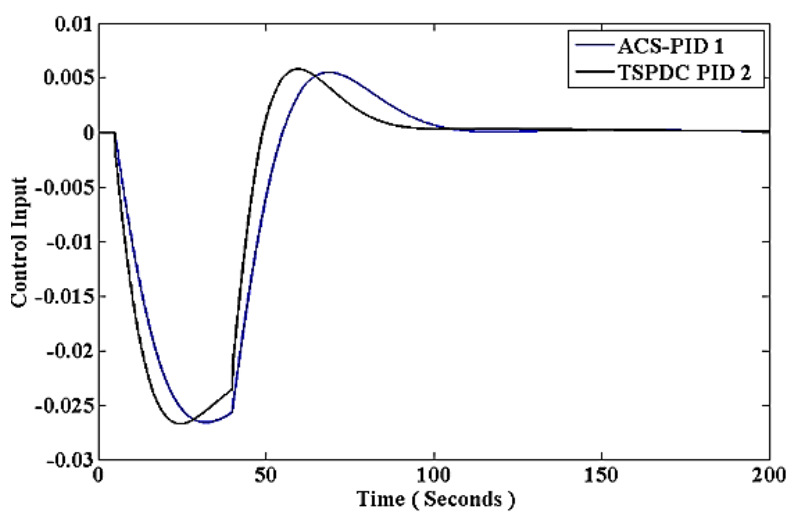

(c)

Figure 16. System dynamic responses case 6, (a) load disturbance, (b) frequency deviation response and (c) control output response

\section{CONCLUSION}

A new strategy for a Takagi-Sugeno fuzzy parallel distribution compensation- PID'S (TSF-PDCPID'S) was implemented to enhance the dynamic response of Egyptian load frequency control (ELFC). The parameters of the operating points of Egyptian load frequency considers as input to a Takagi-Sugeno fuzzy model. The proper optimal PID controller was selected using the Takagi-Sugeno Fuzzy model for a certain operating point. The ACS optimization algorithm used to optimize the parameters values of PID'S controllers at different operating points according to the selected cost function. Several types of disturbances, uncertainty and parameters variations applied on the system to ensure the validation of proposed controller. The simulation results provided that the parallel distribution compensation- PID'S can select the appropriate PID controller at different operating points so, it has a good performance through different kinds of disturbances compared to fixed PID controller.

\section{ACKNOWLEDGMENTS} this work.

I would like to express my special thanks of prof. Abdel Ghany Mohamed for his supporting through

\section{REFERENCES}

[1] Elgerd O. I, "Electric energy systems theory: An introduction," McGraw-Hill, 1971.

[2] Elgerd O. I, and Fosha E., "Optimum Megawatt-Frequency Control of Multi-area Electric Energy Systems," IEEE Transactions on Power Apparatus and Systems, no. 4, pp. 556-563, 1970.

[3] Fosha E. and Elgerd O. I, "The Megawatt-Frequency Control Problem: A new Approach via Optimal Control Theory," IEEE Transactions on Power Apparatus and Systems, no. 4, pp. 563-576, 1970.

[4] Wood, A. J. and Wollenberg, B. F., "Power Generation Operation and Control," John Wiley and Sons Inc., New York, 1994 
[5] Tripathy S. C., Hope G. S. and Malik O. P, "Optimization of Load-Frequency Control Parameters for Power Systems with Reheat Steam Turbines and Governor Dead-band Nonlinearity," IEE Proceedings of Generation, Transmission and Distribution, vol. 129, no. 1, pp. 10-16, 1982.

[6] P. Kundur, "Power System Stability and Control," McGraw-Hill, 1994.

[7] Mostafa H. E., "Artificial Intelligence-Based Load Frequency Control of Multi-Area Power Systems," Ph.D. Thesis, Faculty of Engineering, Ain Shams University, 1999.

[8] Yassin K., Abd-Raboh E. and Al-Domany M. S., "Fast Power System Restoration Via Load Shedding Practices in Egyptian Power System," Mansoura Eng. Journal, vol. 17, pp. 1-20, 1992.

[9] Egyptian Electricity Holding Company, 2007. [Online], Available: http://www.egelec.com/annual\%20report/htm.

[10] Mostafa H. E., "Load Frequency Control of the Egyptian Power System Using Bacterial Foraging Algorithm," Portsaid Engineering Journal, 2012.

[11] G. Magdy, et al., "A Novel Design of Decentralized LFC to Enhance Frequency Stability of Egypt Power System Including Wind Farms," International Journal on Energy Conversion, vol. 6, no. 1, pp. 17-29, 2018.

[12] M. A. Abdel Ghany, "Artificial Intelligent and Static Output Feedback Controllers for Power System Load Frequency Control," M.Sc. Dept. of Electrical Power and Machines Engineering Faculty of Engineering, 2014.

[13] L. Pingkang, Z. Hengjun and L. Yuyun, "Genetic Algorithm Optimization for AGC of Multi-Area Power Systems," IEEE Region 10 Conference on Computers, Communications, Control and Power Engineering. TENCOM'O2. Proceedings, vol. 3, pp. 1818- 1821, 2002.

[14] Rerkpreedapong, D., et al., "Robust Load Frequency Control Using Genetic Algorithms and Linear Matrix Inequalities," IEEE Transactions on Power Systems, vol. 18, no. 2, pp. 855-861, 2003.

[15] M. S Yousuf, H. N. Al-Duwaish and Z. M. Al-Hamouz, "PSO Based nonlinear Predicitive Cobtrol of Single Area Load Frequency," IFAC Conference on Control Applications of Optimization, 2009.

[16] Bensenouci, A., et al., "Simulated Annealing and Dynamic Programming Based Optimum Discrete-Time Output Feedback for a Three-Area Decentralized Load Frequency Control," Proc. 6th CIGRE, 2005.

[17] Bensenouci, A., et al., "Optimal Discrete-Time Output Feedback Control for Multi-Area Load Frequency Control Using Evolutionary Programming," Proc. IEEE Int. Symposium on Industrial Electronics, pp. 366-376, 2005.

[18] E. S. Ali and S. M. Abdel-Elazim, "Bacteria Foraging Optimization Algorithm Based Load Frequency Controller For interconnected Power System," International Journal of Power \& Energy Systems, vol. 33, no. 3, pp. 633-638, 2011.

[19] Daneshfar F. and Bevrani H. "Load-Frequency Control: a GA-Based Multi-Agent Reinforcement Learning," IET Generation, Transmission \& Distribution, vol. 4, no. 1, pp 13-26, 2010.

[20] M. A. Abdel Ghany, A. M. Abdel Ghany, A. Bensenouci, M. A. Bensenouci, M. Nazih Syed Ahmad, "Fuzzy Fractional-Order PID Tuned via Relative Rate Observer for the Egyptian Load Frequency Regulation," The Twentieth International Middle-East Power Systems Conference, pp. 103-109, 2018.

[21] M. A. Abdel Ghany, A.M. Abdel Ghany, A. Bensenouci and M. A. Bensenouci "Fractional-Order Fuzzy PID for the Egyptian Load Frequency Control," The Eighteenth International Middle East Power Systems Conference, pp. 954-961, 2016.

[22] M. A. Abdel Ghany, M. E. Bahgat, W. M. Refaey and F. N. Hassan, "Design Fuzzy Self Tuning of Optimal PID Load Frequency Controller for the Egyptian Power System," Journal of Al Azhar University Engineering Sector, vol. 12, no. 42, pp. 77-89, 2017.

[23] M. A. Abdel Ghany, M. E. Bahgat, W. M. Refaey, and F. N. Hassan, "Design of Fuzzy PID Load Frequency Controller Tuned by Relative Rate Observer for the Egyptian Power System," 9th International Conference on Electrical Engineering, vol. 9, pp. 1-22, 2014.

[24] M. A. Abdel Ghany, H. Abdel Magid, M. Abdullah Eissa, M. E. Bahgat, A. Bassuiny and Soliman Sharaf," Practical Implementation for Fuzzy Self Tuning of Optimal PID Controller to Servo Permanent Magnet Synchronous Motor" Journal of Al Azhar University Engineering Sector, vol. 12, no. 45, pp. 1371-1386, 2017.

[25] K. Tanaka and H. Wang, "Fuzzy Control Systems Design and Analysis: A Linear Matrix Inequality Approach," New York: Wiley, 2001.

[26] T. Guerra, and L. Vermeiren, "LMI-based Relaxed Non quadratic Stabilization Conditions for Nonlinear Systems in the Takagi-Sugeno's Form," Automatica, vol. 40, pp. 823-829, 2004.

[27] H.A. Shayanfar, H. Shayeghi A. Jalili, "Takagi-Sugeno Fuzzy Parallel Distribution Compensation Based ThreeArea LFC Design," IJTPE Journal, vol. 3, pp. 55-64, 2011.

[28] A. Jalili, H. Shayeghi and H.A. Shayanfar, "T-S Fuzzy Parallel Distribution Compensation Controller for Power System Stabilizer," 5th International Conference on Technical and Physical Problems of Engineering, pp. 180-184, 2009.

[29] Purtojo, H. S. B. Rochardjo, G. Nugroho, and Herianto, "Contouring performance study of a fuzzy-based practical controller on an X-Y table,” Int. Conf. Electr. Eng. Comput. Sci. Informatics, vol. 1, no. 1, pp. 63-66, 2014.

[30] P. S. Devi and R. V. Santhi, "Introducing LQR-fuzzy for a dynamic multi area LFC-DR model," International Journal of Electrical \& Computer Engineering, vol. 9, no. 2, pp. 861-874, 2019.

[31] Ho W. K, Hang C. C, and Cao L. S., "Tuning of PID controllers based on gain and phase margin specifications," Automatica, vol. 31, no. 3, pp. 497-502, 1995.

[32] Dorigo M, V. Maniezzo and A. Colorni, "Ant system Optimization by a colony of cooperating agents," IEEE Transaction on Systems Man and cybernetics - part B, vol. 26, no. 1, pp. 29-41. 1996.

[33] Karl O. Jones, and André Bouffet, "Comparison of Ant Colony Optimization And Differential Evolution," International Conference on Computer Systems and Technologies, 2007.

[34] Hadi Nobahari, Seid H. Pourtakdoust, "Optimization of Fuzzy Rule Bases using Continuous ant Colony System," Proceeding of the first International Conference on Modeling, Simulation and Applied optimization, 2005. 
[35] Q. Zeng and G. Tan, "Optimal Design of PID Controller Using Modified Ant Colony System Algorithm," IEEE 3rd International Conference on Natural Computation, 2007.

[36] A.H. Besheer and A. Bensenouci, "Voltage and Power Regulation for a Sample Power System using Ant Colony System Based PID controlle," Journal of Electrical Systems, vol 8, no. 4, pp. 397-410, 2012

[37] F. Hassan, A. Wakeel, A. Kamel and A. Abdel-hamed, "Optimum Tuning of PID Controller for a Permanent Magnet Brushless Motor," Proceedings of the 8th ICEENG Conference, 2012.

[38] M. A. Shamseldin, A. A. El-samahy, and A. M. A. Ghany, "Different Techniques of Self-Tuning FOPID Control for Brushless DC Motor," MEPCON, 2016.

[39] M. Omar, M. A. Ebrahim, A. M, and F. Bendary, "Tuning of PID Controller for Load Frequency Control Problem via Harmony Search Algorithm," Indonesian Journal of Electrical Engineering and Computer Science (IJEECS), vol. 1, no. 2, pp. 255-263, 2016.

[40] M. Omar, A. M. A. Ghany, and F. Bendary, "Harmony Search based PID for Multi Area Load Frequency Control Including Boiler Dynamics and Nonlinearities," WSEAS Trans. CIRCUITS Syst., vol. 14, pp. 407-414, 2015.

[41] M. A. K. El-shafei, M. I. El-hawwary, and H. M. Emara, "Implementation of Fractional - Order PID Controller in an Industrial Distributed Control System," 14th International Multi-Conference on Systems, Signals \& Devices (SSD) Implementation, no. 3, pp. 713-718, 2017.

[42] M. A. Shamseldin and A. A. El-samahy, "Speed Control of BLDC Motor By Using PID Control and Self-tuning Fuzzy PID controller," 15th International Workshop on Research and Education in Mechatronics, 2014.

\section{BIOGRAPHIES OF AUTHORS}
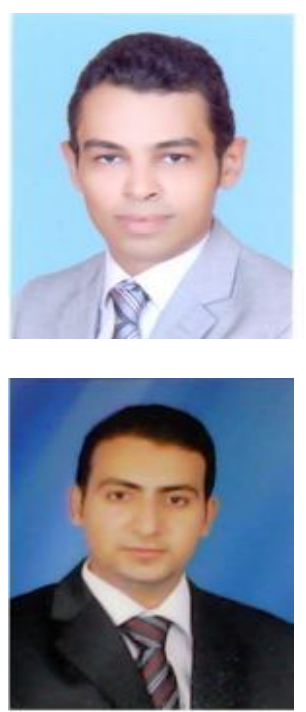

Dr. M A. Abdel Ghany was born in Cairo 22thJuly1988. He received his B. Sc from Higher Technological Institute (Tenth of Ramadan City) 2011, Diploma and M.Sc. in Automatic Control (2012 to 2014) from, Helwan University, Cairo, Egypt. From 20/6/2015 to 2018 he worked as an Assistant Lecturer at Faculty of Computer science Nahda University, Bani Sweif City. He obtained his Ph. D in Automatic Control branch in Faculty of Engineering, Helwan University, Egypt. Now, he worked as a Lecturer at department of Electrical Engineering, Faculty of Engineering October 6 University, Egypt.

Dr. Mohamed. A. Shamseldin born in Cairo, Egypt, on October 1, 1987. He received the B.Sc. degree in mechatronics engineering in 2010 from faculty of engineering at Helwan, Helwan University, Cairo, Egypt. On December 2012, he received his work in faculty of engineering and technology at Future University in Egypt as an instructor in Mechatronics Engineering Department. He obtained M.Sc. in system automation and engineering management (2012 to 2016) from, Helwan University, Cairo, Egypt. Mohamed was visiting staff at University of Central Lancashire, Preston, UK. His research activity includes studying Artificial Intelligent techniques, electrical machines speed control and robot control. 